\title{
Simultaneous fusiform and saccular aneurism of the abdominal aorta severely displacing kidney
}

\author{
Yalcin Solak, ${ }^{1}$ Orhan Ozbek, ${ }^{2}$ Abduzhappar Gaipov, ${ }^{1}$ Suleyman Turk'
}

${ }^{1}$ Nephrology Unit, Department of Internal Medicine, Meram School of Medicine, Konya University, Konya, Turkey ${ }^{2}$ Department of Radiology, Meram School of Medicine, Konya University, Konya, Turkey

\section{Correspondence to} Dr Abduzhappar Gaipov, abduzhappar@gmail.com
To cite: Solak Y, Ozbek 0 Gaipov A, et al. BMJ Case Reports Published online: 18 December 2012 doi:10.1136/bcr-2012006228

\section{DESCRIPTION}

A 76-year-old man presented to our hospital with complaints of left-sided distention of the abdomen and gross haematuria. The patient's medical history included coronary artery disease, hypertension, predialytic chronic kidney disease and abdominal aortic aneurism (AAA). One month prior to current admission the patient was started on haemodialysis. At physical examination there was a prominent swelling on the left side of the abdomen. The mass was not pulsatile. Coronal maximum intensity projection (MIP) image showed (figure 1) partially thrombosed saccular aneurism which fills left side of the abdominal cavity (red arrows), and partially thrombosed fusiform aneurism in distal aorta (green arrows). Widespread atherosclerotic calcifications are evident on the walls of the abdominal aorta and the iliac arteries. The left kidney was severely displaced by the ruptured AAA. The maximum diameter of the fusiform and saccular parts was 6.4 and $23 \mathrm{~cm}$, respectively. Axial slice of the abdominal CT showed (figure 2) indentation of the ruptured abdominal aneurism to anterior abdominal wall, severe displacement of the kidney towards anterior and inferior by bulky haematoma (red arrows) and a calcul in the pelvis of the left kidney (green arrow). The case was deemed inoperable. The patient underwent heparin-free haemodialysis and repeatedly transfused with RBC suspensions. The patient died at 39th day of hospitalisation.

Ninety-five percent of aortic aneurisms are fusiform in shape and the aetiology is degeneration of the vascular wall. In contrast, saccular aortic aneurisms are much less common and most of the time

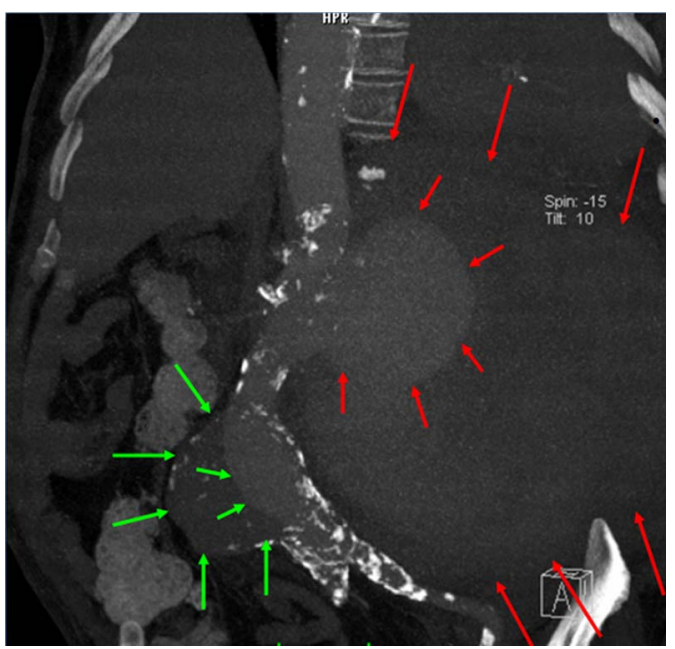

Figure 1 In coronal MIP image shows partially thrombosed saccular aneurism which fills left side of the abdominal cavity (red arrows), and partially thrombosed fusiform aneurism in distal aorta (green arrows).

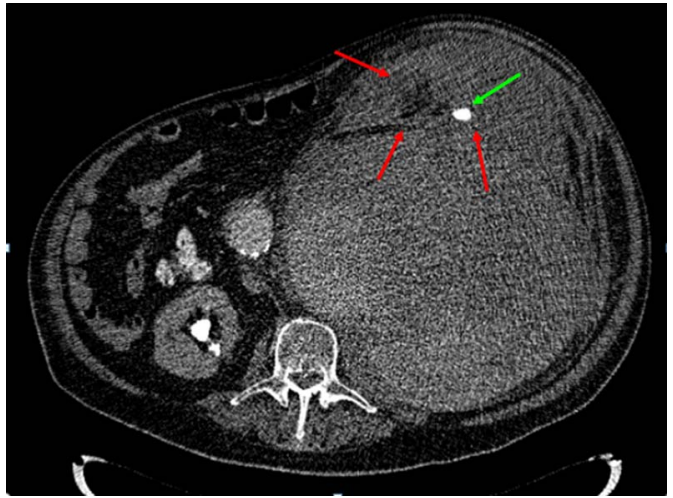

Figure 2 Axial slice of the abdominal CT shows indentation of the ruptured abdominal aneurism to anterior abdominal wall, severe displacement of the kidney toward anterior and inferior by bulky hematoma (red arrows) and a calcul in the pelvis of the left kidney (green arrow).

develop secondary to infection of the aorta. ${ }^{1}$ Rest of the saccular AAA results from a penetrating aortic ulcer. To the best of our knowledge, coexistence of saccular and fusiform aneurisms contiguously in the same patient has never been reported before. This case illustrates a marginal example of a ruptured AAA. The left kidney was displaced severely towards the anterior abdominal wall by bulky haematoma of the saccular aneurism. While amenable to surgery at first, severely expanded aneurism was deemed inoperable at current admission and the patient succumbed to death due to severe internal bleeding.

\section{Learning points}

- Abdominal aortic aneurism is the lifethreatening condition and should be diagnosed as early as possible.

- Abdominal aortic aneurisms should be repaired surgically before the point of no return.

- This is the first report of simultaneous presentation of a saccular and fusiform aneurism in the same patient.

Competing interests None.

Patient consent Obtained.

\section{REFERENCE}

1 Minor ME, Menzoian JO, Raffetto JD. Noninfectious saccular abdominal aortic aneurysm-a report of two cases. Vasc Endovascular Surg 2003;37:353-8. 
Copyright 2012 BMJ Publishing Group. All rights reserved. For permission to reuse any of this content visit http://group.bmj.com/group/rights-licensing/permissions.

BMJ Case Report Fellows may re-use this article for personal use and teaching without any further permission.

Become a Fellow of BMJ Case Reports today and you can:

- Submit as many cases as you like

- Enjoy fast sympathetic peer review and rapid publication of accepted articles

- Access all the published articles

- Re-use any of the published material for personal use and teaching without further permission

For information on Institutional Fellowships contact consortiasales@bmjgroup.com

Visit casereports.bmj.com for more articles like this and to become a Fellow 